\title{
44 T PICTURA MOVENS POESIS": ANÁLISIS TRANSVERSAL DE LA OBRA DE BILL VIOLA Y TERRENCE MALICK
}

CRISTINA SANZ MARTÍN

Universidad de Málaga cristinasanz@usal.es

Resumen: El trabajo del videoartista Bill Viola y del director del cine Terrence Malick no había sido hasta ahora relacionado. Pero la presente investigación probará que las numerosas coincidencias en torno al tratamiento lírico de la imagen, la base conceptual y el trasfondo filosófico no pueden ser fruto de una mera casualidad. Tanto las preocupaciones de orden temático que conforman el imaginario de sendas carreras, así como los recursos audiovisuales utilizados, son totalmente símiles.

Palabras clave: paisaje / naturaleza / videoarte / religión / filosofía / cine.

Abstract: The work of the video artist Bill Viola and the film director Terrence Malick has not been interrelated thus far. But this research will prove that the significant parallelisms about the poetic treatment of the image, the conceptual basis and the philosophical background are not the result of a mere coincidence. Worries about topics conforming both author's worlds of fantasy, as well as audiovisual sources, are in both cases entirely similar.

Key words: landscape / nature / video art / religion / philosophy / cinema.

Este estudio pretende ser una mirada transversal a la obra de Terrence Malick y Bill Viola, ${ }^{2}$ dos artistas norteamericanos que han desarrollado su trabajo en territorios audiovisuales diferentes pero que presentan significativos puntos en común de orden estético, filosófico y conceptual. Aunque sus carreras han sido analizadas individualmente por especialistas de cada uno de sus campos profesionales, creo que es la primera vez que se intenta realizar un análisis transversal de los mismos. Esta investigación surge con el fin de dar respuesta a las numerosas y significativas coincidencias que se aprecian sin esfuerzo, donde una visión poética de la imagen, la expresión de las emociones más íntimas y la búsqueda de un sentido de la transcendencia se materializan en proyectos de narrativa audiovisual y puesta en escena no convencionales, desde una óptica que me atrevo a calificar como "tecno-romántica". "Pantallas sensibles", si se permite la metáfora, que raramente dejan al espectador indiferente, obligándolo a utilizar las imágenes como dispositivos de reflexión sobre la condición humana.

La hipótesis que se plantea es que Bill Viola y Terrence Malick son artistas que trabajan con soportes técnicos diferentes y desarrollan su trabajo dentro de sistemas profesionales que raramente se mezclan. Terrence Malick es considerado uno de los cineastas más legendarios de Hollywood, habiendo ayudado a reformular la narrativa del cine en los años setenta y ochenta y explorando en sus últimas películas puestas en escena más propias del videoarte y el cine experimental que del cine que normalmente se promueve desde la industria. Bill Viola, por su parte, es pionero y precursor del videoarte $y$ ha aportado al medio numerosas innovaciones técnicas y conceptuales, con la paradoja de que, cuanto más compleja y sofisticada se vuelve su obra en lo tecnológico, revela una mayor dependencia de la historia de la pintura.

Analizando las señas de identidad formales y conceptuales de las propuestas audiovisuales de sen-

\footnotetext{
* Fecha de recepción: 15 de abril de 2017 / Fecha de aceptación: 14 de septiembre de 2017.

1 De ahora en adelante me referiré a él mediante las siglas "TM".

¿ De ahora en adelante me referiré a él mediante las siglas "BV".
} 
dos artistas en casi cuarenta años de trabajo, se intentará demostrar que las fuentes filosóficas, literarias, artísticas y vivenciales que surten el imaginario de sus obras transcurren por sendas paralelas y en muchos casos convergentes. Centrados incluso en los mismos temas: como la naturaleza, la religión, el paso del tiempo, la frontera, los límites entre la vida y la muerte, el sentimiento de pérdida, la melancolía o la puesta en escena de las emociones más íntimas.

\section{Breve aproximación biográfica}

Como no parecía casual que sus trabajos se encontrasen visual y conceptualmente tan cercanos, analicé el contexto histórico-cultural desde los años cuarenta (infancia de TM) hasta la década de los setenta (cuando inician ambos su trayectoria artística) tratando de poner en contexto sendas vidas y encontrar así una explicación.

Existen bastantes incógnitas respecto a la biografía de TM y muy especialmente los datos respecto su periplo vital posterior a 1979, siempre se han mantenido dentro de un aura de misterio, siendo únicamente conocidos a través del testimonio de segundas personas. Sin embargo, los pocos datos que conocemos sobre su infancia y formación académica nos parecen imprescindibles para comprender algunos aspectos de su trayectoria. Pueden detectarse una serie de factores que probablemente justifican e impulsan el interés por ciertos temas. Ambos son hijos de inmigrantes europeos. Malick contó desde que nació con esa influencia cultural de Oriente, pues su padre, Emil Malick, era de descendencia líbano-siria y los abuelos paternos de Terrence Malick habían emigrado desde el actual Irán, Viola, por su parte, descubriría Oriente años más tarde durante su juventud y sus viajes, probablemente incentivado por el contexto sociocultural de los sesenta, pues son años de revueltas estudiantiles y del nacimiento de movimientos contraculturales como los beatniks, los hippies o los situacionistas. Los menciono porque, sobre todo en su primera etapa, tanto el trabajo de TM como el de BV encajan en los ideales de la filosofía hippie -interés por la naturaleza y el amor- de los que seguramente se in- fluenciarían en su juventud. La revuelta de "Mayo del 68" en París, las protestas contra la Guerra del Vietnam en Estados Unidos, la reivindicación de los derechos civiles de las minorías raciales, el feminismo y conflictos de género. Todo este clima de apertura mental y libertad, mezclado con las tensiones políticas, influyó en los jóvenes Viola y Malick, los cuales vieron cómo las drogas o las religiones y filosofías orientales pasaban a ser objeto de culto e interés popular. Como el mismo BV declaró: "la generación del Vietnam estuvo muy abierta a las religiones orientales y aquellas enseñanzas espirituales estaban 'flotando en el aire'". El artista se sumerge en esas ideas y crea la base para su trabajo. Igualmente, debido a la corriente oriental, la psicología de la percepción estuvo muy en boga en los sesenta en EE.UU. ${ }^{3}$

Viajar, recorrer el mundo adentrándose plenamente en nuevas culturas y grabando largas horas de celuloide que luego ambos reciclarán en sus trabajos es otro de los puntos a destacar, pues estos viajes les abren las puertas a nuevas formas de pensamiento y conocimiento alternativas a las occidentales (como pueden ser las teorías de la percepción que acabamos de citar, o el ansia de conectar alma y cuerpo, mundo e individuo). Estos viajes están directamente relacionados con ese amor y admiración que ambos tienen por la naturaleza, tema central en ambas producciones. La naturaleza, además, se presenta de la mano de la religión y de la espiritualidad, aunque sometida siempre a una cierta visión orientalizada.

Analizando el contexto histórico en el que ambos artistas crecieron, y aunque lamentablemente en este artículo se alcance a exponer solo en breves pinceladas, se constata que intereses tan allegados no pueden ser casuales, sino más bien causales al haber crecido en el mismo país y con una sola diferencia de diez años.

\section{El concepto de mundo exterior e interior}

-Ver es ser Bill Viola

BV y TM están muy influenciados por el movimiento transcendentalista ${ }^{4}$ y por la mística. Com-

\footnotetext{
${ }^{3}$ Como bien explica Federico Utrera en su libro Viola on Video (2011) p. 42, después de la guerra la psicología de la percepción se asociaba a las ideas de B. F. Skinner y el behaviourismo. Estas teorías hacían hincapié en la idea de la percepción sensorial como una manera de entender cómo el individuo percibe el mundo, se dieron cuenta de que la cultura afectaba a los sentidos y que ampliar las posibilidades de visión tendría como consecuencia ampliar el conocimiento.

${ }^{4}$ Se conoce como Transcendental Club a un grupo de jóvenes intelectuales formado a final del s. XIX en Nueva Inglaterra (EE.UU.) que supuso el nacimiento de la corriente filosófica que se conoce como Transcendentalismo. Algunos de sus integrantes son R. W. Emerson, F. H. Hedge, o H. D. Thoreau.
} 
parten con el transcendentalismo la idea de que el alma del ser se identifica con el alma del mundo, y viceversa. Y, por su parte, la mística les ha influenciado en cómo, mediante sí mismos, pueden alcanzar una experiencia transcendental a través de la percepción del mundo. BV y TM se han preocupado mucho por el mundo físico e interior y de cómo éstos interaccionan entre sí. Para ambos las ideas transcendentalistas y la mística (occidental y oriental) suponen la forma de experimentar, y por tanto, conocer el universo. Sus trabajos pretenden hacer al espectador reconciliarse con su entorno. Me atrevo a afirmar que ambos utilizan la producción de sus obras como una vía de (auto)conocimiento y que, una vez concluidas, pretenden transmitir las preocupaciones que les motivaron a ellos y remover la conciencia del espectador.

Para BV hay dos paisajes: el interior (el individuo) y el exterior (el mundo). El mecanismo a través del cual el individuo "conoce" el mundo es la percepción, y las puertas de la percepción son el resultado del trabajo interdisciplinar del oído, la vista y la cognición. El mundo exterior es, a priori, invisible al individuo, de manera que el sentido de la percepción es el encargado de descifrar al individuo el mundo exterior invisible, y lo que éste capta son imágenes y sonidos. En la misma línea, BV defiende que el mundo interior es real y el mundo exterior es la imaginación. Cuando la gente se pregunta qué es real acude a su interior, a su experiencia individual. ${ }^{5}$ Viola dice que el sentido de la percepción es un medio esencial para el conocimiento, pues hay una realidad que el individuo no está preparado -en sentido de que no tiene las herramientas- para captar. Es por ello que cuando entra en contacto con el hinduismo, el budismo y con los poetas místicos descubre una nueva forma de acercarse al mundo: se da cuenta de que el método occidental de pensamiento falla porque no abarca el cuerpo y la mente juntos. ${ }^{6} Y$ es entonces cuando comienza a estudiar cómo funciona el ojo, cómo funciona el oído y cómo el cerebro integra sus funciones. ${ }^{7}$ Una de sus citas de cabecera, y que viene a reflejar bien esto, es la del artista W. Blake -quien es de gran inspiración para él-, y dice así: "Si las puertas de la percepción estuviesen limpias, entonces todo le parecería al individuo como es, infinito". Una obra clave que ejemplariza esto sería Habitación para San Juan de la Cruz (1983), una videoinstalación formada por una habitación a oscuras que representa el mundo, con un cubo en el centro que representa el ser y una única abertura desde el cubo hacia la estancia que es una minúscula ventana que vendría a simbolizar las puertas de la percepción. Con esta obra el artista explora la relación entre el interior y el exterior del individuo y reflexiona sobre cómo los sentidos de la percepción interactúan con las señales del exterior. Viola recalca la cantidad de información que nos llega y no identificamos poniendo como ejemplo el filósofo contemporáneo Henri Bergson, quien sugiere que los sentidos humanos deberían de ser considerados como "límites" a la cantidad de energía que bombardea nuestro ser, previniendo al individuo de sentirse abrumado al dar una ojeada a la cantidad de información que existe en cada preciso instante. Pero, Viola va aún más lejos afirmando que el problema no es la cantidad de información, sino el no saber gestionarla como es debido. Se trata de discernirla, y es la percepción la encargada de ello. ${ }^{8}$ No es una tarea fácil pero como reiteradamente cita él: "los nuevos órganos de percepción surgen como resultado de la necesidad, aumenta, por tanto, tu necesidad para poder incrementar tu percepción". 9

Por parte de Malick, las únicas vías para adentrarse en su hermético pensamiento son el Transcendental Club y la influencia del pensamiento y las religiones orientales y del cristianismo. Malick comparte con los transcendentalistas su concepción semi-religiosa de la naturaleza. Dios -la naturaleza- es el origen y motor de todo. Un mismo alma que habita dentro y fuera del individuo. Como defendía el líder de movimiento, R. W. Emerson (1803-1882): la verdadera independencia del individuo se consigue por medio de la intuición y la observación directa de las leyes de la naturaleza; cuando el ser se encuentra en contacto con la naturaleza es capaz de conectar con la energía cósmica, fuente creadora de la vida. La naturaleza es divinizada y presentada como el motor de todo, tanto en TM como en BV. En los diálogos de los filmes de Malick se encuentran igualmente

\footnotetext{
5 VIOLA, Bill. 1995, p. 225.

6 UTRERA, Federico. 2011, p. 110.

7 UTRERA, Federico. 2011, p. 148.

8 VIOLA, Bill. 1995, p. 59.

9 VIOLA, Bill. 1995, p. 60.
} 
continuas referencias a Hojas de hierba (Leaves of grass, 1855) de Whalt Whitman (1819-1892):

Escucho y veo a Dios en cada cosa, pero no le comprendo,

$\mathrm{Ni}$ entiendo que haya nada en el mundo que supere a mi yo.

¿Por qué he de desear ver a Dios mejor de lo que ahora le veo?

Veo algo de Dios cada una de las horas del día, y cada minuto que contiene esas horas.

En el rostro de los hombres y mujeres, en mi rostro que reflejo veo a Dios.

Encuentro cartas de Dios dejadas caer en la calle y todas

ellas están firmadas con el nombre de Dios.

Y las dejo donde están porque sé que otras jamás

dejarán de llegar puntualmente $[\ldots]^{10}$

¿Y acaso difieren los versos de Whitman de los diálogos de TM? "Me hablabas a través de ella, hablabas conmigo desde el cielo, los árboles". ${ }^{11} \mathrm{El}$ acercamiento a la naturaleza al que TM nos invita es un acercamiento más contemplativo que el de Viola, la observamos maravillados. Malick pretende sobrecogernos a través de su belleza y su fuerza. Pero recuerda en más de una ocasión que "el Señor nos lo da y el señor nos lo arrebata, Dios es asi" ${ }^{\prime 2}$ nos alude a su omnipotencia. Hay una escena en "El árbol de la vida" (The tree of life, 2011) en la que un dinosaurio está a punto de aplastar la cabeza a otro $y$, finalmente, éste, como concediéndole una indulgencia, le perdona y se va. ${ }^{13}$ Esa escena destaca por la riqueza del lenguaje cifrado: la tensión y angustia que el director crea a través de un simple gesto de demostración de poder, donde un ser que está en posición de superioridad a otro tiene su vida en sus manos. No es un simple gesto. Reflexiona sobre el poder de dios, es decir, de la Naturaleza frente a la insignificancia del individuo. Un dato interesante que no debemos pasar por alto es que Malick acepta la explicación científica sin rechazar sus creencias cristianas. Malick creció en una familia muy religiosa, ¿cómo no serlo en el centro de EE.UU. a mediados del s. XX? Lo vemos en cómo mezcla la primera media hora de "El árbol de la vida" (The tree of life, 2011) que dedica a mostrar la creación del mundo en contraposición con esa mujer vestida de blanco con la que cierra el filme y que nos porta a la imagen preconcebida que tenemos del Espíritu Santo, en un entorno casi celestial y que invita a un grupo de niños a pasar. Además, son imágenes presentadas junto a agua. Como constantemente en Viola, agua como fuente de vida. Es una forma formidable de retratar la creación de vida. ${ }^{14}$

La segunda vía de la que servirse para entender a TM es la cultura y religiones orientales -budismo, hinduismo, sufismo, zen...- y su educación cristiana. Éstas guardan un concepto común: la existencia de un macrocosmos y un microcosmos. Ambos defienden que hay un esquema que se repite de igual manera a diferente escala, una escala real -el universo- y una escala menor -el interior-, es decir, el ser humano como un reflejo del universo. El microcosmos interfiere con el cosmos. Y lo refleja continuamente en su producción: "Oh, alma mía, déjame entrar en ti, mira a través de mis ojos, contempla las cosas que creaste, mira cómo brillan". ${ }^{15}$ En ocasiones ha sido ejemplarizado con la proporción fractal, es decir, la repetición idéntica infinita. BV, probablemente por beber de las mismas fuentes, también comparte este concepto que plasma en algunas obras como Migration (1976) donde enfoca una gota de agua y muestra que las propiedades ópticas de la misma crean una lente en miniatura, y por consiguiente, una imagen de toda la habitación, ${ }^{16}$ una metáfora sobre lo real y lo imaginario, el macro y el microcosmos; en He weeps for you (1976), obra sobre la que reflexiono en la última parte del artículo, también trata el mismo concepto del cosmos a través, también, de una gota de agua. Como cuando Malick dice en "Malas Tierras" (Badlands, 1973) que: "No había una planta en el bosque que no fuese útil", todo es parte de un todo.

Uno de los temas transversales a ambas producciones es el desierto, que suele ser escenario para reflexionar sobre dichas preocupaciones (Fig. 1). El desierto ha sido a lo largo de la historia, especialmente retratado por las mitologías y religio-

\footnotetext{
10 WHITMAN, Walt, 2012, p. 231.

11 MALICK, Terrence. "El nuevo mundo" (The new world, 2005).

12 Fragmento de diálogo (minuto 8.30) del filme "El árbol de la vida" (The tree of life, 2011) de Terrence Malick.

13 Minuto 31:20.

14 Minuto 35:40.

15 MALICK, Terrence. "La delgada línea roja" (The thin red line, 1998)

16 UTRERA, Federico, 2011, p. 97.
} 
nes, un lugar propicio para buscar una experiencia transcendental, una purificación del alma, una vía de escape o un reencuentro del individuo con su propio "yo". El desierto es para ambos un lugar y un tema crucial. Como expone el mismo Viola en su cuaderno de notas personales:

El paisaje puede existir como una reflexión sobre las paredes internas de la mente o como una proyección de un estado interno sobre el exterior. Los espacios abiertos y llanos se prestan a un monitoreo más claro del mundo interior subjetivo. Los espacios urbanos contemporáneos hablan incesantemente... removiendo las sugerencias del exterior, las voces de los estados internos se vuelven más intensos y claros. $^{17}$

Terrence Malick nos coloca al protagonista del "El árbol de la vida" (The tree of life, 2011), Jack O'Brien, deambulando por el desierto en su momento redentorio, esta escena refleja de manera muy acertada la idea del desierto como lugar de búsqueda y reconciliación, la comento detalladamente en la parte de "El ciclo de la vida".

Bill Viola tiene también varias obras que siguen una misma línea estética donde nos presenta a personas que deambulan por el desierto y que parecen perdidas y sin rumbo, por ejemplo Walking on the Edge (2012) o The encounter (2012), el artista explica que esta obra presenta a dos mujeres que caminan por el desierto en fases opuestas de la vida y que recorren cada una su propio viaje, en el momento en el que se encuentran los lazos existenciales se refuerzan y el misterio de la sabiduría viene silenciosamente trasmitido de la más anciana a la más joven, ${ }^{18}$ evidentemente la localización de la obra no ha sido escogida al azar.

\section{El ciclo de la vida}

Todo deviene y fluye, pero una sola cosa permanece, aquella, precisamente, de la que todas estas cosas han nacido para transformarse. Heráclito.

El nacimiento, la vida, la muerte, la regeneración, el paso entre estadios... han sido temas principales desde el principio de sendas carreras. No debemos pasar por alto que Terrence Malick estudió filosofía y que luego se dedicó al cine. La muerte ha es-

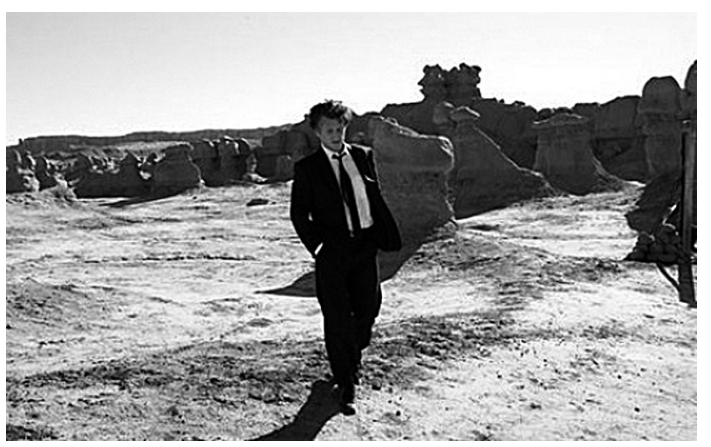

Fig. 1. Momento en el que el protagonista deambula por el desierto en plena catarsis. Fotograma procedente de "El árbol de la vida” (The tree of life, 2011), Terrence Malick.

tado presente en todos y cada uno de los trabajos de Malick, a veces incluso envolviendo la trama principal. Mientras que para BV, la preocupación por el ciclo de la vida ha sido lo que subyace a toda su trayectoria artística, cobrando especial protagonismo en algunas obras. Los dos conciben la vida como un viaje, el paso de un estado a otro y la muerte una transformación. ${ }^{19}$ Analizando sendas carreras puede concluirse un esquema general: existe un ciclo que se repite, porque la existencia, como todo en el universo, también es cambio $y$, por ende, se mueve. Ya se lo decía Séneca a su amigo Lucilio: "pues nos equivocamos, o yo me engaño, querido Lucilio, cuando pensamos que la muerte sigue a la vida, cuando en realidad la precedió y la sigue". ${ }^{20}$ La década de los noventa para Viola está marcada por el ciclo de la muerte y la vida: nace su primer hijo, muere su madre y nace su segundo hijo. Tiene un grupo de obras que giran en torno a esto, por ejemplo: The Passing (1991) donde aparecen diversas fotografías en blanco y negro, en ocasiones ralentizadas como recurso para dejar al espectador reflexionar, de corta duración y sin mucho sentido (aparente) entre ellas, pero se disfrutan de manera global, y en el fondo se observa el tema del transcurso de la vida como un río que fluye de manera incontrolable. No en vano aparece el agua de manera constante en la obra. ${ }^{21}$ En Heaven and Earth (1992) vuelve a confrontar de manera directa la vida y la muerte en dos pantallas que se enfrentan, una arriba (la muerte, en el "cielo") y otra abajo (en la tierra, el nacimiento). Esta preocupación la podemos ver

\footnotetext{
17 ALONSO, Rodrigo. Bill Viola: los senderos de la condición humana. <http://www.roalonso.net/es/videoarte/viola.php>

$18<$ http://atpdiary.com/exhibit/bill-viola/>

19 ALONSO, Rodrigo. Bill Viola: los senderos de la condición humana. http://www.roalonso.net/es/videoarte/viola.php

20 BODEl, Remo, 1995, p. 298.

$21<$ https://neokunst.wordpress.com/2013/06/24/bill-viola-el-videoarte-de-the-passing/>
} 
igualmente envolviendo la trama principal y los diálogos en Malick: "La vida continúa, las personas pasan. Nada permanece igual [...] ¿Cómo llegaste a mí [la muerte]? ¿Bajo qué forma? ¿Con qué disfraz?".22 El cuerpo es el medio para la transformación. Lo que ocurre justo antes de alcanzar la muerte es lo que identifican como transición -recurso constante, por ejemplo en First Light (2002) de Viola-. Así como el Ilamado pneuma ${ }^{23}$ al que ambos también aluden: Viola realizó una obra llamada Pneuma (1994) y grabó a su madre en su lecho de muerte reutilizando dichas imágenes en otras obras -The Passing (1991), Heaven and Earth (1992), Nantes Triptych (1992), por ejemplo-, y Malick también se hace eco en "La delgada línea roja" (The thin red line, 1998): "Me preguntaba cómo sería mi muerte, ¿qué se debe sentir al saber que ese es tu último aliento?". Otra constante preocupación es el "qué hay después de la muerte", Viola hablando sobre su trabajo The Messenger (1996), explicaba que la clave es darse cuenta de que hay un ciclo que se repite continuamente. Como decía Heráclito: "Todo se mueve". Nunca te detienes a pensar en la vida como que "moriré, me desintegraré, pero los hijos seguirán adelante igual que mis padres me concibieron de la nada y yo lo continuaré". Si no ves este ciclo eterno acabarás deprimiéndote y entristeciéndote. ${ }^{24}$ Como decía Epícteto, durante toda la existencia una sola capacidad merece la pena adquirir, la de aprender a vivir, que significa también, y sobre todo, aprender a morir. ${ }^{25} \mathrm{Y}$ nos consta que Terrence Malick también comulga con esta idea de "renovación" como vemos reflejado continuamente en sus trabajos. Todas estas "etapas" del ciclo han sido por lo general tratadas de un modo dramático en nuestra cultura occidental, pero los dos artistas las defienden que no tienen que ser pesarosas porque son etapas del propio ciclo de la vida. En sendas trayectorias la muerte no es nunca el evento que cierra la obra. ${ }^{26}$
Las únicas cosas que son permanentes son la muerte y Dios. Así es.

Eso es todo sobre lo que tienes que preocuparte. No por esta guerra...

No va a ser ni mi fin ni el tuyo [...]

¿Por qué debería de tener miedo? Te pertenezco a ti" 27

"Señor, no apartes de mi tu rostro. Tú no deseas la muerte de un salvador. ${ }^{28}$

Hay una serie de preguntas que han sido intrínsecas a la condición humana desde el comienzo de los tiempos como ¿qué es la muerte?, ¿qué es la vida?, ¿por qué morimos?, ¿hay vida después de la muerte? La trayectoria artística de BV y TM es una continua búsqueda de respuestas a lo que no alcanzamos a responder casi en la misma línea en la que Ingmar Bergman (1918-2007) nos llevó a reflexionar en su célebre filme El séptimo sello (Det sjunde inseglet, 1957), donde un caballero cruzado desafía a la Muerte a una partida de ajedrez. Bergman toca temas que giran en torno a la muerte y a la religión, y a preguntas propias como de las que venimos hablando. Aunque esto no puede ser respondido, solo experimentado. Viola y Malick tampoco pueden dar una respuesta, pero se aproximan a la naturaleza, a los escritores transcendentalistas y a una búsqueda de ente superior para intentar aproximarse. Es curioso que uno de los filósofos que más se ha preocupado por investigar la "condición humana" ha sido Martin Heidegger $^{29}$ quizá esto inspiró a Malick como se refleja en los diálogos de sus largometrajes.

Death in non-movement.

Stillness is life.

Stillness is death.

Stillnes is the root of all life

Death is the root of all life

La muerte no es movimiento

La calma es vida

La calma es muerte

La calma es la raíz de toda vida

La muerte es la raíz de toda vida

BV notas, $1980 .{ }^{30}$

22 MALICK, Terrence. "El árbol de la vida" (The tree of life, 2011).

23 Pneuma es una antigua palabra griega que se refiere al último suspiro antes de abrazar la muerte.

24 GARCÍA ROMERO, Beatriz. "Entrevista a Bill Viola: pionero del videoarte". <http://www.revistadearte.com/2009/07/12/ entrevista-a-bill-viola-pionero-del-videoarte/>.

25 BODEl, Remo, 1995, p. 296.

26 FORNASIERO, Andrea, 2007, p. 206.

27 MALICK, Terrence, "La delgada línea roja" (The thin red line, 1998).

28 MALICK, Terrence, "El nuevo mundo" (The new world, 2005).

${ }^{29}$ Como cuenta F. Utrera en Viola on Video, TM ganó una beca Rhodes para realizar su doctorado en el Magdalene College de Oxford. Pretendía estudiar el concepto de "mundo" y "ser" en Heidegger, pero en aquella época, éste aún no se tomaba con la suficiente consideración como para dedicarle una tesis y su director, Stanley Cavell, lo rechazó.

30 VIOLA, Bill, 1995, p. 77. 
Como Heráclito explicaba: "el fuego vive en la muerte del aire y el aire en la muerte del fuego, el agua vive en la muerte de la tierra y la tierra en la muerte del agua". ${ }^{31}$ Los cuatro elementos suponen en repetidas ocasiones el eje sobre el que se desarrollan diversos trabajos. Por ejemplo, con el tema que estamos tratando está muy relacionado el elemento del agua. El agua ha sido, es y será fuente de vida. Pueden rastrearse numerosos momentos en los que ambos artistas vinculan la salvación al agua, por ejemplo, en Malas Tierras (Badlands, 1973) la libertad y la vida para Kit se acaba en las badlands, ${ }^{32}$ o durante todo el filme de La delgada línea roja (The thin red line, 1998) el agua se personaliza constantemente como el elemento esencial para seguir vivos: “QQué pasa con el agua? No está llegando aquí arriba. Mis hombres están apunto de desmayarse, señor",33 destaca esa preocupación constante por tener agua en mitad de una durísima batalla. Y en "El árbol de la vida" (The tree of life, 2011) durante la secuencia de la creación, TM comulga con la teoría de que los primeros organismos unicelulares nacieron del electromagnetismo causado por la entrada en contacto del magma con el agua, e igual opina BV:

Todos venimos del agua, la vida en la tierra empieza con las bacterias, los peces, las ballenas, el hombre [...]. El agua es el elemento con mayor presencia en todos los elementos del mundo, tiene muchas propiedades materiales, y es la primera composición del cuerpo cuando creamos vida, se protege dentro del vientre de las mujeres. Es una sustancia esencial, fundamental y profundamente espiritual. Da la vida, pero también se la puede llevar. ${ }^{34}$

Viola tras una experiencia cercana a la muerte por ahogamiento siendo niño, quedó muy señalado y ha dado al agua un papel protagonista desde el principio, como TM, ligada al concepto de vida, tránsito o regeneración, catártica y purificadora.

Sin duda, entre toda la producción audiovisual de Viola y Malick, hay una obra y una secuencia que me llamaron la atención desde el principio por su belleza estética, por su tratamiento poético de la imagen y por su precisión conceptual. Éstas son: Nantes Triptych (1992) (Fig. 2) de BV y la secuencia

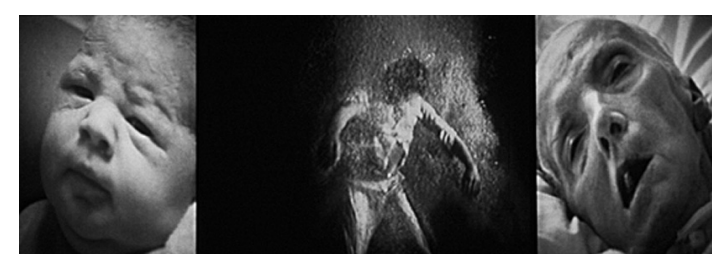

Fig. 2. Fotograma procedente de "El tríptico de Nantes" (Nantes Tryptich, 1992), Bill Viola.

final ${ }^{35}$ de "El árbol de la vida" (The tree of life, 2011). La videoinstalación de Viola supone una interconexión espiritual entre el nacimiento, la vida y la muerte representadas simultáneamente. La obra contrapone la llegada y la ida, separadas por un hombre que flota -ien tránsito?- en el elemento esencial para la creación de vida: el agua. Con Malick el concepto nos queda claro desde el principio de "El árbol de la vida" (The tree of life, 2011) cuando al ir presentando el mundo nos introduce un plano de una vidriera en espiral, podría pasar desapercibido pero en Malick nada es casual. La espiral ha guardado desde antaño un significado relacionado con la eternidad, con el ciclo, además, el contexto religioso de dicha vidriera y la luz resplandeciente que entra a través de ella nos habla de dios. Volviendo a la secuencia final, podemos resumir toda la idea que ha ido desarrollando a lo largo de dos horas de película en un momento catártico que comulga con el ciclo vital que se viene exponiendo. La película ${ }^{36}$ iniciaba con la muerte de uno de los hermanos y estos últimos diez minutos son una clara redención. La secuencia empieza con un Jack adulto (Sean Penn) en un ascensor subiendo-digamos al cielo-. Comienza a hablarle a su hermano. $Y$ atraviesa con miedo y duda una puerta - ¿es una frontera? ¿Es el cruce de la muerte de su hermano?- en medio del desierto, localización que no es azarosa. Tras atravesar la puerta Jack comienza a rezarle a su hermano como si estuviese ya en el cielo: "hermano, vela por nosotros. Guíanos. Hasta el fin de los tiempos". El mismo Jack adulto, completamente perdido, comienza a seguirse a sí mismo (sigue al Jack niño) a la deriva por el desierto. Se suceden una serie de imágenes cuya iconografía nos remite a dios -una escalera al cielo, la mano de una

\footnotetext{
31 FORNASIERO, Andrea, 2007, p. 242.

32 Como cuenta F. Utrera en Viola on Video, la inapropiada traducción de "malas tierras" se traduce en un conjunto geográfico de tierras baldías que destacan por su sequía y la falta de vegetación.

33 MALICK, Terrence. "La delgada línea roja" (The thin red line, 1998).

34 MARTínEZ, Federico, 2011, p. 197.

35 Desde el minuto 120 del filme.

36 El filme se considera un trasunto autobiográfico de TM, siendo Jack quien interpreta a Terrence.
} 
joven de blanco que parece encarnar al Espíritu Santo, puertas, etc.-, nos introducen hasta un lugar remoto, una playa en la que Jack se reencuentra con toda la familia, y no sólo. El agua subyace a toda la secuencia de forma alarmantemente simbólica, pero también intercala planos donde el agua se manifiesta de forma individual, como por ejemplo: hay una escena en la que dos corrientes de agua se enfrentan como si la muerte y la vida se encontrasen. Esta secuencia donde numerosas personas participan del momento de redención de forma individual me remite a BV en "Las Pasiones" donde los actores experimentan su propia lucha ajenos al mundo exterior y también a The Encounter (2012) o Ancestors (2012) por la similitud de la estética. Todos los gestos en estos planos están cargados de contenido. Volviendo a la playa, Jack se reencuentra con sus padres, luego con su hermano fallecido, y después son los padres los que encuentran al pequeño, y entonces, todas las personas que deambulaban por la playa como almas perdidas comienzan a dirigirse hacia el mar. Tras ello vemos una puerta, es destacable que la puerta esta sumergida bajo el agua: una puerta bajo el agua que se abre para dejar al alma irse, de nuevo muerte y agua, agua y vida. La riqueza iconográfica de cada detalle es altísima. Y vuelve a introducir varias secuencias del mar, de las olas, de unas cataratas... Malick no dice nada pero revela todo. Seguidamente los padres despiden a su hijo en una habitación sin techo -significativo al hablar de libertad-. Tras la despedida, la madre entrega al espíritu santo el alma de su hijo. Los gestos están cargados de contenido en estos planos, hablan solos. Tras la entrega aparecen unos girasoles que Malick nos presentó al principio del filme y que miraban para abajo, ahora miran al cielo. $Y$ Jack vuelve a aparece en un ascensor pero ahora bajando, ¿a la tierra? Tras esto un plano de un puente: ¿vuelta a empezar?

Hay más casos donde las coincidencias de orden estético y conceptual llamaron mi atención. Por ejemplo, para "La delgada línea roja" (The thin red line, 1998) TM graba unas escenas -que luego reciclará en "El árbol de la vida" (The tree of life, 2011)- donde el soldado Witt aparece nadando junto a unos indígenas. Son imágenes de vida y felicidad en el agua, imágenes que en otra secuencia del mismo filme se reciclan siguiendo a las de la escena de la propia muerte de Witt. Mismas imágenes, muerte y agua, muerte y vida. La inmersión como regeneración ha sido adoptada por varios credos como un tránsito religioso. ${ }^{37}$ Estas imágenes subacuáticas de una gran riqueza conceptual tienen una estética que llama fácilmente la atención por su parecido a las de la obra de BV, por ejemplo en Tristán e Isolde, entre otras.

\section{La puesta en escena de las emociones}

Durante mucho tiempo las pasiones han sido condenadas como un factor de perturbación o de pérdida temporal de la razón. En tanto que signo manifiesto de un poder extraño a la parte mejor del hombre, dominarían a éste, distorsionando su clara visión de las cosas y desviando su propensión al bien. ${ }^{38}$ Pero desde su tecnoromanticismo, Viola y Malick siempre se han preocupado por el estudio de las emociones. BV en su serie "Las Pasiones" Ileva a cabo su intento más ambicioso. Igualmente lo hace TM, especialmente desde la segunda etapa (1998) el nivel de tensión emocional va in crescendo y se manifiesta de una manera muy particular, más cercana al trabajo de Viola que al cine comercial. Es cierto, como defendía Eva Illouz, que la era del capitalismo ha alimentado una intensa cultura emocional favoreciendo las emociones como mercancías, en una gran variedad de lugares sociales, desde la literatura de autoayuda, las revistas femeninas y los grupos de apoyo, hasta las nuevas formas de sociabilidad nacidas en Internet. ${ }^{39}$ Hoy día estamos acostumbrados a ser manejados a través de la publicidad, la televisión o la prensa, pero no es tan común que "el producto" que puede llegar a manejarnos implique accionar todos nuestros sentidos, recuerdos y experiencias, utilizando las imágenes como dispositivos de reflexión que continúan actuando en nuestra mente después de haberlas visionado, como ocurre con las producciones de ambos (Fig. 3).

Pero sin duda, lo más llamativo de BV y TM no es la conmoción emocional en la que sumergen al consumidor, sino el cómo. La apelación a todos los sentidos en clave simbólicamente sinestésica. ¿Cómo puede sentirse el tacto, el olfato o el gusto en la pantalla? ${ }^{40}$ En una entrevista a E. Lubezki -director de fotografía de TM-, declaró que el propósito era siempre crear destellos de momentos

\footnotetext{
37 MARTínEZ, Federico, 2011, p. 197.

38 BODEl, Remo, 1995, p. 11.

39 ILLOUZ, Eva, 2007.

${ }^{40}$ Luciana Caresani en la mesa redonda organizada por la revista de cine Marienbad con motivo del estreno de "El árbol de la vida" (The tree of life, 2011).
} 


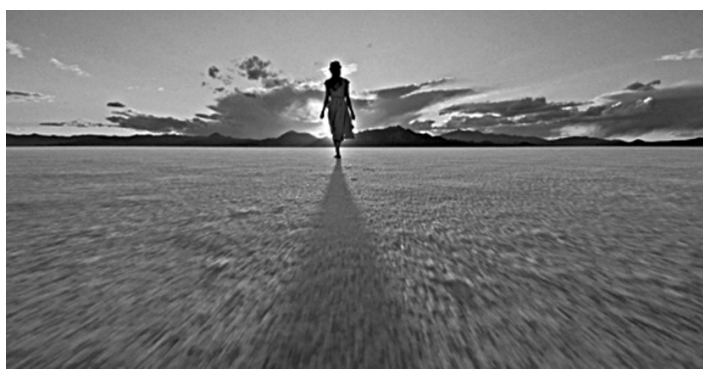

Fig. 3. Tras despedir a su hijo, la madre camina por la inmensidad de la nada, en una escena envuelta de una cargada simbología religiosa. Fotograma procedente de "El árbol de la vida" (The tree of life, 2011), Terrence Malick.

naturales. ${ }^{41}$ Mediante el estudio de las emociones, Viola pretende entender cómo funcionan éstas, aunque sin obviar que el factor cultural, y por consecuencia el perceptivo, influye en el manejo de las mismas. Diría que tanto BV como TM entienden la audiovisión en los términos en los que la formulaban teóricos de la imagen como $\mathrm{M}$. Chion: "no se ve lo mismo cuando se oye, no se oye lo mismo cuando se ve". ${ }^{42} \mathrm{Y}$ por audio se entiende también el silencio, gran recurso de ambos para ensalzar aún más la imagen, como dejando que nuestra mente en calma piense con claridad. La clave para lograr sobrecogernos así es explotar todos los recursos del soporte (privación del audio, ralentización, experiencia inmersiva de la videoinstalación...) alterando la naturaleza audiovisual de la imagen, de manera que los órganos sensoriales se concentren en lo que el artista quiere. Esta búsqueda a toda costa de lirismo audiovisual es uno de los puntos más relevantes en ambas carreras, sus imágenes se caracterizan por una gran belleza e invitan a un sobrecogimiento poco habitual. Ningún plano ha sido integrado por una mera cuestión estética, todo encierra un significado. Este cuidado esteticismo, que a primera vista pudiera parecer gratuito, está puesto al servicio de las ideas que se intentan transmitir e incluso detalles en apariencia anecdóticos o insignificantes -como, por ejemplo, una imagen de pájaros sobrevolando la escena- se prestan a las más complejas interpretaciones y deben ser vistos como parte de una totalidad. Sus trabajos se transforman -y de algún modo pretenden transformar al observador- en cada visionado, convirtiéndose el espectador así en co-creador.

Una estrategia común para potenciar las emociones es el uso de referentes compositivos e iconográficos que derivan de la historia de la pintura, es decir, recurren al "inconsciente pictórico". ${ }^{43} \mathrm{En}$ algunos trabajos de ambos el movimiento fílmico está retenido o "suspendido", como si se tratara de cuadros autónomos mediante largos planos fijos en los que los movimientos de las figuras se producen de un modo tan ralentizado que a veces resulta casi imperceptible, por lo que podríamos hablar de "pintura en movimiento" o de "tableaux vivants en celuloide". En la misma medida, citan composiciones, iluminación, color, motivos iconográficos y puestas en escena que derivan de la pintura medieval, renacentista o decimonónica que revelan un vocabulario compartido entre la pintura, el cine y el videoarte que alcanza grados de conexión sorprendentes. Además, Viola cuanto más se desarrolla tecnológicamente, más se vincula con la historia de la pintura. Aunque investigar a fondo sobre las relaciones del trabajo de BV y TM con la historia de la pintura desborda los límites de esta investigación, algunas de las referencias relevantes son, por ejemplo: Johannes Veermer (1632-1675) cuya influencia en el uso de la luz, destacando las ventanas, se palpa fácilmente (Fig. 4) o William Blake (1757-1827) del que Viola ha declarado ser discípulo, quizá le fascinó el hecho de que se adelantase rompiendo las barreras que separan las artes e integrando pintura y poesía. También Edward Hooper (1882-1967), tanto por referencias arquitectónicas muy literales -por ejemplo, en "Días de cielo" (Days of Heaven, (1978) cita a "Railroad" (1925) de forma explícitacomo por su tratamiento de la luz, del color y por la capacidad que tienen algunos de sus cuadros más famosos para producir la sensación de "tiempo suspendido", algo muy perseguido por ambos artistas. Y por último e indudablemente más destacable: Caspar David Friedrich (1774-1840) con sus visiones abismales de la naturaleza y el trata-

41 B, Benjamin, "Emmanuel Lubezki, ASC, AMC creates emotionally resonant imagery for Terrence Malick's The Tree of Life", ASC, 2011, http://www.theasc.com/ac_magazine/August2011/TheTreeofLife/page4.php

42 Luciana Caresani en la mesa redonda organizada por la revista de cine Marienbad con motivo del estreno de "El árbol de la vida" (The tree of life, 2011).

${ }^{43}$ Véase el texto de presentación de la exposición de F. J. Panera Cuevas: El inconsciente pictórico celebrada en el MNAC de Barcelona. Se puede consultar en la página web del museo: http://www.museunacional.cat/sites/default/files/ premsa loop_cast_0.pdf El asunto es tratado a fondo por el mismo autor en su libro: Emociones formales. Reflexiones sobre el inconsciente pictórico en la fotografía contemporánea, Junta de Castilla y León, 2004 y en Video Killed The Painting Star. Pintura e imagen en movimiento, CITA / Festival de Cine de Medina del Campo, 2010. 


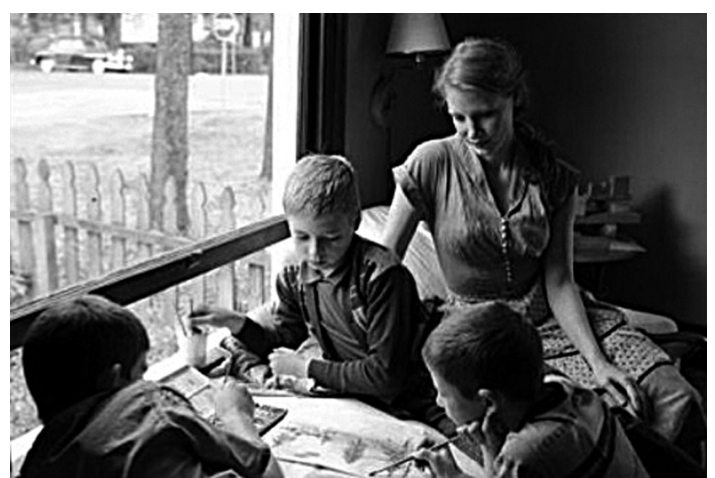

Fig. 4. Escena junto a la ventana de clara influencia "veermeriana" donde destaca el estudio del uso de la luz natural. Fotograma procedente de "El árbol de la vida" (The tree of life, 2011), Terrence Malick.

miento de la figura humana respecto a la inmensidad de los mares, bosques y montañas, así como el misticismo otorgado al paisaje y a la arquitectura.

Por otro lado, como he dicho, conseguir alzar al espectador hasta tal sobrecogimiento emocional es un complejo proceso y para ello se sirven de una inmensidad de recursos. Ambos materializan su angustia transcendental en imágenes de gran fuerza poética casi en los mismos términos en que algunos románticos perseguían la abstracta idea de lo sublime. Un estado de sobrecogimiento en el que el miedo y el placer se encuentran y ello nos lleva a un estado semiinsconsciente donde se recrean a rienda suelta las emociones, que como Susan Sontag dijo, "para que [las fotografías] las imágenes acaso alteren una conducta han de conmover". ${ }^{44} \mathrm{Y}$ aunque adentrarse en ello ahora sería algo osado y casi imposible, debía al menos ser mencionado.

En el mismo orden, un componente esencial para recrear dicha sensación es la luz. Para los dos la luz se vuelve un tema totalmente prioritario e incluso obsesivo, pero particularizándolo en Malick con sus estudios de ventanas y su obcecación por grabar durante "la hora dorada" tratando de alcanzar la luz perfecta. Ésta también encierra una simbología: la luz es un recurso constante para representar a dios. El uso de Viola de la luz es diferente, pues utiliza iluminación de estudio y las imágenes llegan a manipularse digitalmente para potenciar determinados efectos en la fase de postproducción, sin embargo sus intenciones al tratar esta técnica no distan mucho de las de TM.
Otro recurso que querría evidenciar es el paralelismo en el repertorio gestual utilizado por ambos. Un ojo crítico y educado se percatará súbito de que para los dos artistas, y me atrevería a decir que aún más en Malick, el lenguaje gestual cobra un papel determinante. Hay un número infinito de planos y secuencias dedicados a gestos, a veces solo manos que acarician el viento. Los gestos en TM son como una válvula de escape para gritar lo que siente y piensa, pero no está permitido expresar por medio de las palabras. TM introduce un lenguaje basado en gestos en "El nuevo mundo" (The new world, 2005) y lo desarrolla en todo su esplendor en "El árbol de la vida" (The tree of life, 2011). Viola no se aleja mucho. Durante los primeros años de su carrera estaba centrado en otros temas, pero el lenguaje corporal comienza a cobrar real importancia -desde una dimensión claramente teatral y en ocasiones performativa- a partir de la serie de "Las Pasiones". Pero, quizá la diferencia es que su lenguaje gestual no parece englobar principalmente una expresión verbal -como es el caso de Malick-, sino espiritual o emocional. Destacan algunas piezas donde el estudio de los gestos supone el tema central de la obra, el estudio de las pasiones, encierra una búsqueda del entendimiento del ser humano, como decía Spinoza, "las pasiones humanas [...] son necesarias para entender la naturaleza humana", 45 Four hands (2001), Silent Mountain (2001) o The quintet of the astonished (2000) son claros ejemplos de esto, como defiende Remo Bodei: conocer las pasiones (las emociones) es analizar la razón misma iluminándola con su misma sombra presunta;4 y en la misma línea pero algo más cercano al trabajo de Malick, The encounter (2012) y Emergence (2000), entre otros. La imagen ralentizada o privada de audio enfatiza el poder de comunicación de esos gestos, el silencio y ese "tiempo suspendido" nos ofrecen tiempo para observar y reflexionar los cambios graduales -tanto físicos como mentales- que se van produciendo.

\section{La particular visión de la espiritualidad y la naturaleza en Malick y Viola}

Tú eres nuestra madre, nosotros tu maizal. Nos alzamos tras brotar de ti. ${ }^{47}$ -Pocahontas

Si la producción de Viola y Malick tuviese que ser definida en breves palabras, sin duda, hablaría-

44 La cursiva es de la autora. SONTAG, Susan, 2013, p. 73.

45 BODEl, Remo, 1995, p. 81.

46 BODEl, Remo, 1995, p. 14.

47 MALICK, Terrence. En "El nuevo mundo" (The new world, 1998). 
mos de naturaleza y religión. La diferencia primordial, en cuanto al trato de la religión, es que Malick es creyente, un fortísimo creyente, y encarna a dios en todos y cada uno de los elementos o recursos que utiliza; mientras que Viola, aunque habla de religión y de espiritualidad, mezcla -dependiendo de la pieza y de la etapa de su vidaOriente (zen, budismo, sufismo, hinduismo...) y Occidente (cristianismo). Así pues, más que decir que Bill Viola habla de dios o que sus trabajos hablan de religión, diríamos que éste utiliza sus obras como un medio para expresar y buscar su particular versión de la espiritualidad. Sobre la espiritualidad de TM poco se puede decir, ya que no hay pista alguna más allá de lo que deja entrever en sus trabajos por medio del lenguaje audiovisual y los diálogos. A pesar de su condición cristiana, el dios que plasma es sus películas es un dios veterotestamentario inmerso en una simbología proveniente del Nuevo Testamento. Su idea de dios se rastrea muy bien en el "Libro de Job" del Antiguo Testamento, donde ideas como la presencia y aceptación del dios castigador pero que te ama, sobre la vida y la muerte o sobre la creación del mundo se plasman de manera directa en sus trabajos. Para Malick, dios no es un dios misericordioso como el cristianismo presenta; sino un dios cruel y castigador como el que encontramos en el judaísmo. Su idea de dios la refleja muy bien en "El árbol de la vida" (The tree of life, 2011) al representar el castigo, el poder, la exigencia y la tormenta en su padre y brindar el amor incondicional, la gracia, la belleza y la armonía a través de su madre ${ }^{48}$ (Fig. 5). Ya las iniciales del propio nombre del protagonista -Jack O'Brien- remiten al nombre de "Job". Y, en efecto, Jack -como Jobdebe discernir su propio camino a pesar de todas las dificultades que le son impuestas. Por ejemplo: "Él es quien hace la llaga, y él la vendará. Él hiere, y sus manos curan". ${ }^{49} \mathrm{O}$, en la misma línea, "Yahveh dio, Yahveh quitó". ${ }^{50}$ En el filme, una vecina viene a consolar a la madre tras la muerte de alguien y le dice: "el Señor nos lo da y el Señor nos lo arrebata. Él es así. Envía moscas a las heridas que él debería curar".

Sobre BV tenemos mayor información, fue educado en una familia cristiana, pero en su adolescen-

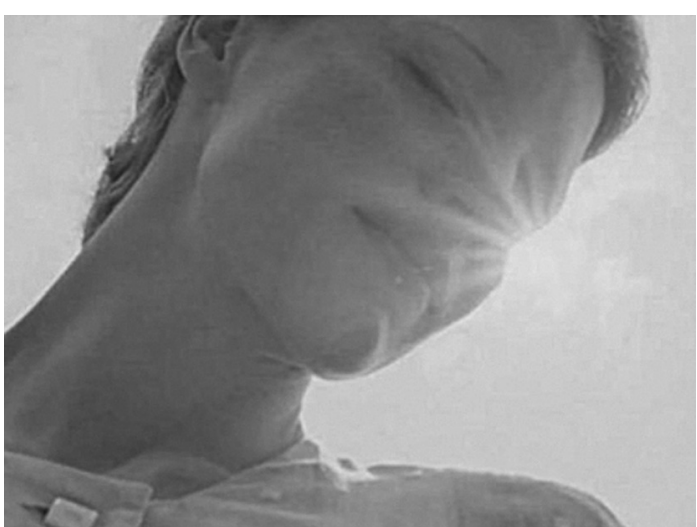

Fig. 5. A través de la figura de la madre, Terrence Malick representa la bondad y armonía de dios. Fotograma procedente de "El árbol de la vida" (The tree of life, 2011), Terrence Malick.

cia, y seguramente influido por la atmósfera del movimiento hippie, comienza a interesarse por la mixtificación de religiones que procedían de Oriente, y se da cuenta de que el acto de percepción en sí es una forma viable de conocimiento. Así que formula su propia selección ecléctica de disciplinas y filosofías para tejer una red que se acerque todo lo posible al conocimiento absoluto que incluye: física cuántica, metafísica, psicología de la percepción, antropología, mitología y la antigua filosofía griega. ${ }^{51}$ Tras este primer contacto con el lejano y desconocido Oriente, se va a vivir a Florencia donde se reconciliará con el arte medieval y renacentista que tanto había rechazado siempre, allí también descubre a uno de sus escritores de cabecera: el poeta místico musulmán Yalal al Din Rumi (1207-1273). Tras ello se mudará a Japón, tercer momento de inflexión en su vida al encontrarse con una cultura milenaria y viva. Viola declararía sobre estas experiencias que: "Me di cuenta de que no sólo estaba aprendiendo diferentes estilos de vida, sino también diferentes sentidos del ser". 52 Lo que aprendió iba mucho más allá de viajar y ver nuevas culturas, aprendió a comprenderse mejor a sí mismo en toda la inmensidad de su ser y lo trata en su trabajo desde entonces (Fig. 6).

Para diseccionar el trabajo de Viola y Malick, además de la vertiente religiosa, se encuentra la vía

\footnotetext{
48 URÍA, Ignacio, 2012, p. 41.

49 Libro de Job. Antiguo Testamento. Capítulo 7. Versículos 17 y 18.

50 Libro de Job. Antiguo Testamento. Capítulo 1. Versículo 21.

51 UTRERA, Federico, 2011, p. 42.

52 UTRERA, Federico, 2011, p. 92.
} 


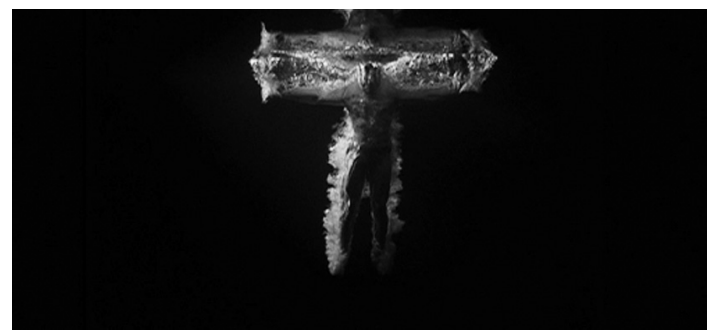

Fig. 6. Fotograma procedente de Five Angels for the Millenium, 2001, Bill Viola.

cosmológica, ${ }^{53}$ es decir, la naturaleza. Para TM, la naturaleza es Dios, y viceversa. Es el arma que éste emplea para manifestarse. Lo vemos en "El nuevo mundo" (The new world, 2005) cuando Pocahontas se pregunta: "Madre [naturaleza], ¿dónde vives? ¿En el cielo, en las nubes, en el mar? ¡Muéstrame tu rostro, dame una señal!". La vegetación, al encarnar a dios, "da y quita": la naturaleza aparece como belleza, paz y armonía, pero también como cruel y castigadora. La vida vegetal encierra numerosos peligros, como vemos en "La delgada línea roja" (The thin red line,1998): "Mira esta jungla, mira aquellas plantas trepadoras. Como se enredan entorno a los árboles tragando todo. La naturaleza es cruel". Los personajes de Malick tienen un lazo muy fuerte con la naturaleza aunque a menudo la destruyan, sientan poco respeto por ella o no sepan cómo relacionarse con ella. ${ }^{54}$ Pero, ¿y acaso difiere de la relación del ser humano con dios? ¿O de la relación de los seres humanos con el resto de seres humanos de su entorno? Malick parece reflexionar sobre el comportamiento natural del hombre hacia la vida y hacia su entorno. La naturaleza es un motor de acción, un ente "creador" que abruma y se plasma a través de inhóspitos y sublimes paisajes que nos recuerdan constantemente su poder ${ }^{55}$ y nuestra insignificancia, como en Viola. Es una naturaleza en silencio, que parece observar en calma y de modo inmutable los actos ridículos y presuntuosos que lleva a cabo el ser humano. ${ }^{56}$ Pero nunca desde lo moral o narrativo, y siempre desde lo sensorial, o a través de lo fugaz, de instantes irrepetibles que, en su misma esencia, llegan a convocar una tensión psíquica y espiritual muy difícil de describir, por la belleza de sus imágenes o por lo desgarrador y lacerante de sus escenas. ${ }^{57}$ En Malick, los árboles parecen catedrales, las plantas cobran un papel majestuoso e importante y los animales protagonizan largos minutos de metraje. ${ }^{58}$ Los diálogos de sus películas parecen encarnar auténticas plegarias a la Madre Naturaleza:

¿Quién eres tú que vives bajo todas estas formas? Tú la muerte que captura todo. Tú, también, eres la fuente de todas las formas que van a nacer. Tú gloria, misericordia, paz, verdad. Tú brindas calma y espíritu, entendimiento y valentía [...] Quizá todos los hombres tienen un mismo alma al que todos pertenecen [...] Cada uno como un ascua dibujado a partir del mismo fuego. ${ }^{59}$

En cuanto a BV, su obra es la combinación de una cosmología ecléctica y personal, creada a partir de Occidente y Oriente. A BV la naturaleza le atrae en modo espiritual, en sintonía con las filosofías orientales. Pretende ahondar en las leyes intrínsecas del cosmos y en su dimensión transcendente para entender mejor al ser humano, pues defiende que "una conducta arrogante con la naturaleza solo nos llevará a la autodestrucción" . 60 Uno de los momentos más cruciales de su vida tuvo lugar en un viaje al desierto del "Death Valley" (California, 1973). Tras ello declaró lo siguiente -que además debe ponerse en relación con varios temas que hemos tratado hasta ahora-:61

Sentí que una parte de mí estaba saliendo hacia los cientos de millas de la cordillera y abarcándolo todo. Llegado a un punto, empecé a asustarme. Sentí el paisaje tan enorme que si yo me perdía allí nadie me habría encontrado. Y Dios podría bajar y como si

\footnotetext{
53 La cosmología es la ciencia que trata las leyes generales que configuran el universo, pero también se entiende como el conocimiento filosófico de las leyes generales que rigen el mundo físico.

54 MASSANET, Adrián. "'Malas Tierras' y la inocencia asesina”. Blog de cine. 2009. <http://www.blogdecine.com/criticas/terren ce-malick-malas-tierras-y-la-inocencia-asesina>

55 POVEDANO, Marina; TOMÁS, Adrián, 2014, pp. 53-60.

56 HAX, Andrés. "Vida y obra: Terrence Malick". 2013. <http://www.revistaenie.clarin.com/Vidas-Breves-Terrence_Malick_0_841116116.html>

57 MASSANET, Adrián. "El arte más allá de lo narrativo", 2011. <http://www.blogdecine.com/criticas/el-arbol-de-la-vida-arte-mas-alla-de-lo-narrativo>

58 FORNASIERO, Andrea, 2007, p. 277.

59 MALICK, Terrence. "La delgada línea roja" (The thin red line,1998).

60 UTRERA, Federico, 2011, p. 146.

61 UTRERA, Federico, 2011, p. 99.
} 
fuera un "bichito", sacudirse de mí bien lejos. Y tuve dos revelaciones: que estamos conectados profundamente con todo el cosmos y que al mismo tiempo somos mortales, frágiles e intranscendentes; la búsqueda del significado en que los seres humanos han estado involucrados desde el inicio de los tiempos es parte de la reconciliación de estas dos cosas.

Estas declaraciones de Viola me devuelven a Malick y me remiten a su primer largometraje "Días de cielo" (Days of Heaven, 1978), cuando Linda cuenta que en la campaña de recogida del trigo... "había gente de sobra, podían contratar a cuantas personas quisieran. Si no trabajabas, te echaban". Malick piensa constantemente acerca de la insignificancia e intranscendencia del individuo, la vuelve a expresar en "La delgada línea roja" (The thin red line, 1998) mediante el coronel Tall en el momento en el que escupe a sus soldados que... "en este mundo, un hombre en sí no es nada. $Y$ no hay más mundos que éste".

Esto se materializa en la obra He weeps for you (1976). Viola creó esta obra en el año 1976, cuando estaba entrando en contacto con las filosofías orientales. Pero también rastreamos la influencia occidental en el mismo nombre ("Él llora por ti") encierra una connotación cristiana, la cámara se centra en una gota de agua que se forma en una pequeña válvula de latón que es ampliada y proyectada en una gran pantalla en donde los espectadores pueden ver un enorme primer plano de la gota de agua que se está formando y en la que descubren que aparece un reflejo invertido de ellos mismos y de una porción de la habitación, la gota cae lentamente hasta chocar con un tambor, en el que retumba un sonido que ha sido amplificado y que representa la destrucción de un mundo microcósmico, el de la gota. La gota, minúsculas porciones de agua que la conforman, y millones de pequeñas gotas que conforman un mar, como cada individuo que forma parte de un todo, como hablábamos en el apartado de "El concepto de mundo exterior e interior". Otro de los elementos a destacar es la relación que establece entre el universo y la naturaleza. Como explica el artista, la gota de agua es un elemento natural y la cámara de vídeo uno tecnológico. Así muestra la relación entre la creación humana y el universo.

\section{Bibliografía}

Primaria

VIOLA, Bill. Reasons for knockning at an empty house: Writings 1973-1994. Robert Violette (ed.), Londres: The MIT press, 1995.

Secundaria

BODEI, Remo. Geometría de las pasiones. Miedo, esperanza, felicidad: filosofía y uso político. Barcelona: Muchnik Editores, 1995.
CATTANEO, Francesco. Mitografie della modernità. Pisa: Cineforum, 2006.

FORNASIERO, Andrea. Terrence Malick: Cinema tra classicità e modernità. Genova: Le Mani, 2007.

ILLOUZ, Eva. Intimidades congeladas: Las emociones en el capitalismo. Buenos Aires: Katz, 2007.

MAHER, Paul. One Big Soul: an oral history of Terrence Malick. Gran Bretaña: Amazon, 2014.

PANERA, Javier. Emociones formales. Salamanca: Junta de Castilla y León, 2004.

PÉREZ ORNIA, José Ramón. El arte del vídeo: Introducción a la historia del video experimental. Madrid: RTVE/ Serbal, 1991.

RUSH, Michael. Videoart, Londres. Thames \& Hudson: 2007.

SANTAMARÍA, Alberto. El idilio americano: ensayos sobre la estética de lo sublime. Salamanca: Ed. Universidad de Salamanca, 2005.

SONTAG, Susan. Ante el dolor de los demás. Aurelio Major (trad.). $2^{a}$ ed. Barcelona: Debolsillo, 2013.

TOWNSEND, Chris. The art of Bill Viola. Londres: Thames \& Hudson, 2004.

UTRERA, Federico. Viola on Video. Madrid: Servicio de Publicaciones y Difusión de la Universidad de Las Palmas de Gran Canaria, 2011.

WENDT, Selene; BARRAGÁN, Paco. When a painting mo ves... Something must be rotten! Milán: Charta, 2011.

WHITMAN, Whalt. Hojas de hierba, $3^{\circ}$ ed., Manuel Villar Raso (trad. y pról.). Madrid: Alianza Editorial, 2012.

Terciaria.

Catálogos:

AA.VV. Las Pasiones. Barcelona: Fundación La Caixa, 2000.

Artículos Hemeroteca:

DELORME, Stéphane. "En torno al gesto". Cahiers du Cinema, 2011, $n^{\circ} 48$, pp. 13-14.

MARTÍNEZ UTRERA, Federico. "Agua y medioambiente en el videoarte de Bill Viola". Cuaderno interdisciplinar de desarrollo sostenible. 2011, n 6, p. 195-221.

TORO, Mandy. "Lo infinito en el Barroco, lo sublime y el Arte Contemporáneo". SituArte, 2007, n 9, pp. 51-61.

URÍA, Ignacio. "Terrance Malick Filosofía en $16 \mathrm{~mm}$ ". Nuestro Tiempo, 2012, n672, pp. 34-40.

POVEDANO, Marina; TOMÁS SAMIT, Adrián. "Prisiones de luz. La arquitectura en Terrence Malick y El árbol de la vida". L'ATALANTE, 2014, n²17, pp. 52-60.

Documentos y recursos 'on line':

ALONSO, Rodrigo. "Bill Viola: los senderos de la condición humana", http://www.roalonso.net/es/video arte/viola.php (Fecha de consulta: 20-8-2016).

ALONSO, Rodrigo. "Análisis de 'El árbol de la vida'", http://www.taringa.net/posts/reviews/13072012/Ana lisis- de-The-Tree-of-Life-Terrence-Malick.html (Fecha de consulta: 25-8-2016).

ARMAS, Jonay. "La estética en el cine de Terrence Malick", http://labutacaazul.com/estetica-en-el-cine-dete rrence-malick. (Fecha de consulta: 24-8-2016).

B, Benjamin. "Emmanuel Lubezki, ASC, AMC creates emotionally resonant imagery for Terrence Malick's 'The Tree of Life'", https://www.theasc. com/ac _magazine/August2011/TheTreeofLife/page1.php (Fecha de consulta: 10-8-2016). 
FREELAND, Cynthia. "Bill Viola and the sublime art". En Film Philosophy, 1999, http://www.film-philosophy. com/vol3-1999/n28freeland (Fecha de consulta: 19-82016).

GARCÍA ROMERO, Beatriz. "Entrevista a Bill Viola, pionero del videoarte", 2009, http://www.revista dearte.com/2009/07/12/entrevista-a-bill-viola-pione rodel-videoarte/ (fecha de consulta: 10-09-2016).

LATSIS, Dimitrios. "Rosy-Fingered Dawn: The Natural Sublime in the work of Terrence Malick", 2010, http:// refractory.unimelb.edu.au/2010/07/18/r-o-s-y-f-i-n-ge-r-e-d-d-a-w-n-the-natural-sublime-in-the-work-ofterrence-malick-\%E2\%80\%93-dimitrios-latsis/ (Fecha de consulta: 30-8-2016).

MASSANET, Adrián. "'Días de cielo', el lirismo de los miserables", 2009, http://www. blogdecine.com/criti cas/terrence-malick-dias-del-cielo-el-lirismo-de-losmiserables (Fecha de consulta: 24-8-2016).

MASSANET, Adrián. "'El árbol de la vida': arte más allá de lo narrativo", 2011, http://www.blogdecine. com/criticas/el-arbol-de-la-vida-arte-mas-alla-de-lonarrativo (Fecha de consulta: 24-8-2016).

MASSANET, Adrián, "'El nuevo mundo', deconstruyendo el mito", 2010, http://www.blogdecine.com/criticas/ terrence-malick-el-nuevo-mundo-deconstruyendo-elmito (Fecha de consulta: 24-8-2016).

MASSANET, Adrián. "'El nuevo mundo', el renacer de John Smith", 2010, http://www.blogdecine.com/criti cas/terrence-malick-el-nuevo-mundo-deconstruyen do-el- mito (Fecha de consulta: 24-8-2016).

MASSANET, Adrián."'El nuevo mundo, la muerte del amor", 2010, http://www.blogdecine.com/criticas/te rrence-malick-el-nuevo-mundo-la-muerte-del-amor (Fecha de consulta: 24-8-2016).

MASSANET, Adrián, "'La delgada línea roja' - el paraíso interior", 2009, http://www.blogdecine.com/criticas/ terrence-malick-la-delgada-linea-roja-completamen te- perdidos (Fecha de consulta: 24-8-2016)

MASSANET, Adrián. "'La delgada línea roja' - En el barco", 2009, http://www.blogdecine.com/criticas/terren ce-malick-la-delgada-linea-roja-paraiso (Fecha de consulta: 24-8-2016)

MASSANET, Adrián. "'La delgada línea roja' - la vida contra la muerte", 2009, http://www.blogdecine. $\mathrm{com} / \mathrm{criticas} /$ terrence-malick-la-delgada-linea-rojala-vida-contra-la-muerte (Fecha de consulta: 24-82016).

MASSANET, Adrián. "'La delgada línea roja' - Paraíso", 2009, http://www.blogdecine.com/criticas/terrencemalick-la-delgada-linea-roja-paraiso (Fecha de consulta: 24-8-2016).

MASSANET, Adrián. "'La delgada línea roja' - viaje hacia la línea", 2009, http://www.blogdecine.com/criti cas/ terrence-malick-la-delgada-linea-roja-paraiso ( $\mathrm{Fe}$ cha de consulta: 24-8-2016).

MASSANET, Adrián. "'Malas Tierras': huyendo a ninguna parte", 2009, http://www.blogdecine.com/criticas/ terrence-malick-malas-tierras-huyendo-a-ningunaparte (Fecha de consulta: 24-8-2016).
MORGAN, David. "Spirit and Medium: The Video Art of Bill Viola" en Image 2, 2015, http://imagejournal. org/ page/journal/articles/issue26/morganthevisualarts (Fecha de consulta: 18-4-2015).

PANERA, Javier. "El inconsciente pictórico", http:// www.museunacional.cat/sites/default/files/premsa_lo op_cast_0.pdf (Fecha de consulta: 10-9-2016).

"Mesa redonda sobre 'El árbol de la vida'", 2012, http://www.marienbad.com.ar/mesaredonda/el-arbolde-la-vida-terrence-malick (Fecha de consulta: 13-82016).

Material audiovisual

BERGMAN, Ingmar. Det sjunde inseglet, 1957, Suecia, (96 min.).

DANTAS, Marcello; NADER, Carlos. Territorio do Invisivel, 1994, Centro Cultural Banco do Brazil (dir.), (24 min.).

KOGI, Martin. Cameras are soul keepers. Dir. Louisiana Museum of Modern Art. 2011. (28 min.). Disponible en: https://www.youtube.com/watch?v=uenrts2YHdl.

MALICK, Terrence. Badlands, 1973, EE.UU., (94 min.).

MALICK, Terrence. Days of Heaven, 1978, EE.UU. (171 $\min$.$) .$

MALICK, Terrence. The thin red line, 1998. EE.UU. (179 $\min .-215 \mathrm{~min}$.).

MALICK, Terrence. The new world, 2005. EE.UU. (135min.-172min. -150 min.).

MALICK, Terrence. The tree of life, 2011. EE.UU. (139 $\min$.).

VIOLA, Bill. Migration (1976), EE.UU. (7min.).

VIOLA, Bill. Room For St. John the Cross, 1983. EE.UU. (14min.).

VIOLA, Bill. He weeps for you, 1986.

VIOLA, Bill. The Passing, 1991 (54 min.)

VIOLA, Bill. Heaven and Earth, 1992.

VIOLA, Bill. Nantes Triptych, 1992, EE.UU. (29 min.).

VIOLA, Bill. The Pasions, 2000

VIOLA, Bill, Iconic Turn: Bill Viola - Video Art, Sense Perception and Human Experience, 2003, $142 \mathrm{~min}$. Disponible en: https://www.youtube.com/watch?v=IY13 $\mathrm{Z}$ ocVePU

VIOLA, Bill. The encounter, 2012.

VIOLA, Bill, The movement in the moving image, 2009. Disponible en: https://www.youtube.com/watch?v=t0 RCkNugozU

Material radiofónico

"Entreviste Bill Viola et Kira pour sa exposition au Grand Palais". En France Culture, http://www.france culture.fr/player/reecouter?play $=4801906$

"Interview with Bill Viola" En $B B C$, http://www. bbc. co.uk/programmes/b020vp15 RNE.

"Art Nation. Bill Viola extended interview". En $A B C$ Australia, http://www.abc.net.au/arts/stories/s3039333.htm

"Interview with Bill Viola". En Aspen Public Radio, http://aspenpublicradio.org/post/audio-canvas-bill-viola 